\title{
Ethical aspects of paper publication: An observational survey among PG residents
}

\author{
Rohit Sane ${ }^{1}$, Pradeep R Jadhav ${ }^{2}$, Siddharth Dubhashi ${ }^{3}$, Noopur Vyas ${ }^{1}$, Jigar Bhatt ${ }^{1}$, \\ Indu Slathia ${ }^{1}$ \\ ${ }^{1}$ Tutor, Department of Pharmacology, MGM Medical College \& Hospital, Navi Mumbai. \\ ${ }^{2}$ Associate Professor, Department of Pharmacology, MGM Medical College \& Hospital, Navi Mumbai. \\ ${ }^{3}$ Professor and Head, Department of Surgery, MGM Medical College \& Hospital, Navi Mumbai. \\ Corresponding Author: Rohit Sane \\ E-mail: rohitsane7@hotmail.com
}

\begin{abstract}
Background: A well-made research is a cumbersome process. The submission of a research article for publication is the final stage of long planning, execution, analysis, and final preparation of the research document. Concerns have been raised about the gradual decline of ethical principles that guide scientific research as well as writing and publication. Postgraduate residents (PG) are in their interim phase of education, research and practice. MCI guidelines has made mandatory for PG's to pursue research as a part of academic requirement. There exists paucity in literature on the ethical aspects of publication among PG residents. To assess the level of understanding of PG residents with respect to the ethical norms of paper publication.

Methodology: A cross-sectional, observational questionnaire survey was conducted among PG's pursuing education at a tertiary care teaching hospital, Navi-Mumbai. A total of 60 PG's were included. The questionnaire included aspects of ethics, authorship, conflict of interest, plagiarism, simultaneous submission and salami slicing.

Result: Majority of the PG residents were involved in research and published research paper. Majority (83.33\%) followed ICMR guidelines for publication. The correct criteria for authorship were known to only 5\%. A large fraction knew what conflict of interest $(68.3 \%)$ and plagiarism (86.6) meant. The terms simultaneous publication (35\%), duplicate publication (31.6\%) and salami slicing $(26.6 \%)$ were poorly known.

Conclusion: The overall ethical understanding of $\mathrm{PG}$ residents with respect to paper publication was low. Further, structured CME/workshop on ethics and paper publications need to be planned to reduce the knowledge gap.
\end{abstract}

Key words: Postgraduate, ethics, publication, awareness, plagiarism, knowledge.

\section{INTRODUCTION}

Ethics taken from the Greek word 'ethikos,' is defined as a set of principles or a system of right conduct. From a medical or research point of view, the ethical conduct is important as it directly affect the humanity [1]. The ever-growing medical science pools scientific evidences, in it on a daily basis. A well-made research is a cumbersome process. The submission of a research article for publication is the final stage of long planning, execution of research, tedious analysis, and final preparation of the document [2].

Research misconduct is defined by the Royal College of Physicians of Edinburgh, "as any behavior by a researcher, whether intentional or not, that fails to scrupulously respect high scientific and 
ethical standards [3-4]. Various types of research misconduct include the following; fabrication or falsification of data, plagiarism, problematic data presentation or analysis, failure to obtain ethical approval by the Research Ethics Committee or to obtain the subject's informed consent, inappropriate claims of authorship, duplicate publication, and undisclosed conflict of interest $[1,5]$. Over the years, there has been a gradual decline of ethical principles that guide scientific research as well as writing and publication. A growing commercialization of research with its effects on the ethical conduct of researchers and the advancement of scientific knowledge are of concern today and need serious thought [1]. The misconduct in research and publication not only affects other authors, but reviewers and editors along with the patient and the scientific community [1].

The World Association of Medical Editors (WAME) has laid guidelines on the publication ethics policies for medical journals and authors on various issues such as study design and ethics, authorship, peer review, editorial decisions and plagiarism [5]. Postgraduate residents are in their interim phase of education, research and specialty clinical practice. Recent Medical Council of India (MCI) guidelines has not only made mandatory for all PG's to pursue research as a part of academic requirement, in the form of dissertation but also to engage in research activities and publish their researches in medical journals [6].

There exists paucity in literature on the ethical aspects of publication among PG residents in India therefore; our study aims to find the level of understanding of an ethically sound research paper publication and ethical norms to a PG resident.

\section{METHODOLOGY}

This study was a prospective, cross-sectional, observational, questionnaire-based survey. The study was conducted at a Tertiary care teaching medical college \& hospital in Navi-Mumbai and had a study period of 3 months. Permission of the Institutional Ethics Committee (IEC) was taken. An informed written consent was taken from each participant before being included in the study. The study included PG residents currently pursuing MD/MS course, irrespective of age, sex or specialty. Non-PG residents, participants below the age of 18 years and those not willing for informed consent were excluded from the study.

The survey tool was a predesigned, pretested and structured questionnaire, which assessed the participants understanding on issues of Ethics, Authorship, Conflict of Interest, Plagiarism, Simultaneous submission and Salami slicing. Individual participants were approached and their responses to the study questionnaire were assessed. Data obtained was entered in MS-Excel 2010 and analysed. Numerical data was summarized using Mean and Standard Deviation. Categorical data was expressed using percentage.

\section{RESULT}

A total of sixty PG's participated in the study. Out of the total, $48.3 \%$ were males (29) and $51.7 \%$ were females (31). The male: female ratio was 0.94 . The mean age of study participants was 27.27 \pm 2.6 years.

Out of the total participants, $96.67 \%$ were undergoing research activity, as a part of Dissertation $(70 \%)$ or non-dissertation related (26.67\%). Out of them $48.33 \%$ were publishing papers, as a part of dissertation, non-dissertation or both.

In the Ethics section, majority (83.33\%) participants followed ICMR guidelines for research studies. Majority obtained IEC approval prior to commencement of study. Very few presented at conferences $(8.3 \%)$ or published in journals $(6.67 \%)$ without IEC.

In the Authorship section, $58.33 \%$ were aware of the authorship criteria but only $5 \%$ had correct knowledge of it. Majority knew that Ghost authorship and Guest / Gift authorships were ethically wrong. In the Conflict of Interest section, $68.33 \%$ were aware and only $41.67 \%$ had correct knowledge of it.

In the Plagiarism section, $86.67 \%$ were aware of plagiarism and $76.65 \%$ had correct knowledge of it. Few knew that substantial copying; text recycling and paraphrasing contributed towards plagiarism and was ethically wrong. 
In the Simultaneous and Duplicate Publication section, $35 \% \& 31.67 \%$ respectively were aware whereas only $31.67 \%$ \& $20 \%$ respectively had correct knowledge of it.

Around $26 \%$ were aware and had correct knowledge of Salami Slicing. Majority rated their knowledge and research skills as average (5.4 out of 10$)$ for publication.

\section{DISCUSSION}

The key findings of this study signify gaps in the knowledge of PG's regarding ethical aspects of paper publications. Ethical breaches can be intentional or can arise simply out of ignorance or lack of adequate knowledge [2]. The gradual decline of ethical principles that guide scientific research as well as writing and publication is a rising issue. The misconduct in research and publication not only affects other authors, but reviewers and editors along with the patient and the scientific community [1]. In this pilot study, an attempt has been made to study the level of understanding of PG's on ethical aspects of research paper publication and ethical norms. In this study, majority of the PG's were undergoing research activities, either in the form of their thesis or other individual research. Around equal number of participants were involved in the process of publishing papers. In the Ethics section, we observed that majority PG's followed ICMR guidelines for research studies. We also observed that majority obtained IEC approval prior to commencement of their studies. Such ethical and correct practices according, to the World Association of Medical Editors (WAME) and the Indian Council of Medical Research (ICMR), were followed correctly by majority of the PG's. However $6.67 \%$ published papers in journals without IEC. This amounts to scientific misconduct as many depend on medical journal and papers for the newer trends and treatment modalities of diseases. The readers of these papers get improper information, scientific flawed research and compromise their skills in treating aliments. Following proper procedures and getting proper IEC approvals eliminates these issues as the committee approves these research studies, on the basis of scientific and ethical aspects, which indirectly help humanity acquiring proper robust information.

In this study, majority PG's lacked sufficient knowledge of the Authorship criteria's. However, majority knew that Ghost authorship, Guest and Gift authorships were ethically wrong. It was similarly reported by Rennie D, et. al., where they found the knowledge of authorship to be inadequate and the criteria's to be termed author were unfulfilled [7]. The submission of a research article for publication is the final stage of long planning, execution of research, tedious analysis, and final preparation of the document [2]. Thus, authors who put in so much of efforts to make one piece of article should rightfully deserve credit for their efforts, contribution and participation. If not given, then disputes can be raised amongst the authors leading to rivalry and bitterness. Now days, to get a publication under your name is considered a academic status symbol and people come up with newer and newer ways to get, more and more publications under their belts. This again increases the pool of medical articles leading to loss of space, time of the reviewers and loss of humanity in all. In order to restrict such unethical issues, one needs to set clear expectations and contributions of individual authors from the outset. Goals should be established before commencement of the study and a broader picture of the research should be kept in mind.

Conflict of interest is crucial in a non-bias publication. Majority PG's were aware of conflict of interest and only less than half had correct knowledge of it. There are two types of conflict of interests; i.e. direct \& indirect [8]. Direct comprises of employment, stock ownership, grants, patents, etc. Whereas indirect comprises of honoraria, mutual fund ownerships, paid expert testimonies, etc. Undeclared financial conflicts may seriously undermine the credibility of the journal, the authors, and science itself [8]. Full disclosure about a relationship that could constitute a conflict-even if the person doesn't believe it affects their judgment-should be reported to the institution's ethics group and to the journal editor to which a paper is submitted. All publishers require disclosure in the form of a declaration letter and/or footnote in the manuscript [9]. Thus PG's should be sensitized and made aware of this fact. To minimize such events, one should explicitly state the potential conflict of interest, declaring the nature of the conflict, source of 
funding and its role. This will allow the journal to adequately send to unbiased reviewers and thus minimize bias.

In the Plagiarism section, most of the PG's were correctly aware and had correct knowledge of it. Few knew that substantial copying; text recycling and paraphrasing contributed towards plagiarism and was ethically wrong. One of the most common types of publication misconduct is plagiarism-when one author deliberately uses another's work without permission, credit, or acknowledgment. Plagiarism takes different forms, from literal copying to paraphrasing some else's work and can include: data, words \& phrases, ideas \& concepts [8]. Plagiarism is easier to commit with the progress in the field of the Internet [10]. Whenever a manuscript is submitted, the editorial teams perform a literature search and most of the time it is possible to detect an already published text, passage. Detection of plagiarism used to be difficult in the past. The web-based data is easier to be detected [10]. Authors should be thus made aware of the consequences of copying another's work. The first author is responsible for any and all misconducts related to the manuscript [1]. The authors should therefore keep track of all the sources while researching and quote them. They should fully acknowledge the source and reference them properly.

Simultaneous submission occurs when a person submits a paper to different publications at the same time, which can result in more than one journal publishing that particular paper [10]. Duplicate/multiple publication occurs when two or more papers, without full cross-reference, share essentially the same hypotheses, data, discussion points, and/or conclusions [11]. This can occur in varying degrees: literal duplication, partial but substantial duplication, or even duplication by paraphrasing [9]. In our study, we observed that majority had poor knowledge on Simultaneous and Duplicate Publication. Authors should submit their manuscript to one journal only. They should not send it to multiple journals in order to increase their chances of having a publication. We also found that knowledge of PG's about Salami slicing was poor. The cutting of research that would form one meaningful paper into several different papers is called salami publication or salami slicing. By making multiple articles from one article increases the pool of medical articles leading to loss of space, time of the reviewers and loss of research credibility.

Currently, MCI has made it mandatory for all PG's to pursue research as a part of academic requirement for MD/MS courses [6]. Thus, structured CME's and workshops are warranted to enhance the research and ethics skill of the PG's. International bodies like WAME, ICMJE and COPE have released guidelines on basic research conduct and research publication $[5,8,11]$. The PG's to gain an insight on it should refer and adopt these guidelines.

The study had a few limitations. It was a pilot study with a small sample size. The study was conducted at a single tertiary care centre; therefore, the findings cannot be generalized to the whole population. Further studies with larger sample size and multiple setups need to be conducted for a broader picture of the existing knowledge gaps.

\section{CONCLUSIONS}

The overall ethical understanding of PG residents with respect to paper publication was low. Further structured CME/Workshops on ethics and paper publications should be planned to reduce the knowledge gap. Thus, paving a way to help them improve their understanding and knowledge in future.

\section{REFERENCES}

1. Jain AK. Ethical issues in scientific publication. Indian J Orthopaed 2010;44(3):235-237.

2. Benos DJ, Fabers J, Farmer J, Jessica P, Gutierrez, Hennessy K. Ethics and scientific publication. Adv Physiol Educ 2005;29:59-74.

3. Gilbert FJ, Denison AR. Research misconduct. Clin Radiol 2003;58:499-504.

4. Pitak-Arnnop P, Schouman T, Bertrand JC, Hervé C. Comment éviter la non-conformité de la recherche biomédicale. Recommandations aux chirurgiens. J Chir (Paris) 2008;145:534-41. 
5. World Association of Medical Editors. [Cited 2017 October 10]. Available from: http://www.wame.org.

6. Medical Council of India (MCI). Postgraduate Medical Education Regulations. Available from: https://www.mciindia.org/documents/rulesAndRegulations/PostgraduateMedical-Education-Regulations-2000.pdf.

7. Rennie D, Flanagin A, Yank V. The contributions of authors. JAMA 2000;284:89-91.

8. International Committee of Medical Journal Editors. Uniform Requirements for Manuscripts Submitted to Biomedical Journals: Ethical Considerations in the Conduct \& Reporting of Research: Conflict of Interest. [Cited 2017 December 2]. Available from: https://www.icmje.org/conflicts-of-interest/.

9. Elsevier. Ethics in Research \& Publication. August 2015. [Cited 2017 October 10]. https://www.publishingcampus.elsevier.com/websites/elsevier_publishingcampus/files /Guides/Brochure_Ethics_2_web.pdf.

10. Fiona G. Plagiarism and punishment. BMJ 2007;335:7627.

11. Committee on Publication Ethics Guidelines on Good Publication Practice. Committee on Publication Ethics (COPE). 1999. [Cited 2017 November 15]. Available from: https://publicationethics.org/files/u7141/1999pdf13.pdf.

Acknowledgements - Nil

Source of Funding - Nil

Conflict of Interest $-\mathrm{Nil}$ 